\title{
ROL DE LA MUJER ECUATORIANA EN LA ESCRITURA CIENTÍFICA, CASO DE ESTUDIO: UNIVERSIDAD CENTRAL DEL ECUADOR
}

\author{
ROLE OF ECUADORIAN WOMEN IN SCIENTIFIC WRITING, \\ CASE STUDY: UNIVERSIDAD CENTRAL DEL ECUADOR
}

\author{
Gladys Morejón Caizal Alba Narváez Coronel²
}

\begin{abstract}
Resumen
La mujer actual ha logrado un alto reconocimiento en el campo científico por sus aportes e investigaciones; sin embargo, cabe destacar que no siempre fue así, pues las ideologías antiguas sembraron la idea de que las mujeres no podian aportar de manera trascendente al desarrollo de la ciencia. Este trabajo se realizó con el objetivo de determinar el grado de participación femenina en la escritura de artículos científicos. Para ello, se desarrolló un análisis sobre la evolución de la producción científica de las y los docentes universitarios. Se comparó los aportes de los autores y las autoras de artículos científicos correspondientes a tres áreas primordiales: Ciencias de la Vida y Salud, Ciencias Exactas y Ciencias Sociales en los periodos comprendidos entre el 2014-2018 y 2016-2018.

Los datos se tomaron del Portal de Revistas de la Universidad Central del Ecuador (UCE), de aquellas publicaciones que se encontraban en dicho espacio hasta el primer semestre de 2019, para realizar el estudio se dividieron los aportes de los autores y autoras en internos/as y externos/as. El trabajo se realizó en la ciudad de Quito, provincia de Pichincha y se aplicó la metodología de tipo cuantitativo: se efectuó conteo de datos, los que se utilizaron en el análisis estadistico para establecer las diferencias de autores y autoras. Como resultados destacados se encontró que la mayor cantidad de artículos se produjo en 2017, tanto interna como externa, con el 58.3 \% correspondiente a los autores y $41.6 \%$ perteneciente a las autoras lo que hace notar un $16.7 \%$ de diferencia en la escritura científica distribuida en cada una de las áreas definidas.
\end{abstract}

Palabras clave

Artículos, ciencia, docencia, escritura, investigación, mujer.

\begin{abstract}
Today women have a considerable place in science, however, this was not always the case, as ancient ideologies sowed the idea that women can contribute to science. The research was carried out with the objective of making visible the degree of female participation in the writing of scientific articles. For this, an analysis was developed on the evolution of the scientific production of fourth-level teachers. The contributions of the authors of scientific articles corresponding to three main areas were compared: Life and Health Sciences, Exact Sciences and Social Sciences in the periods between the 2014 - 2018 and 2016-2018

The data was taken from the Portal of Journals of the Central University of Ecuador (UCE), of those publications that were in said space until the first semester of 2019 and to carry out the study the authors were divided into interns and external. The work was carried out in the city of Quito, Pichincha province. The quantitative methodology was applied: data counting was carried out, which were used in the statistical analysis to establish the differences of authors and authors. As outstanding results, it was found that the largest number of articles was produced in 2017, both internally and externally, with $58.3 \%$ corresponding to the authors and $41.6 \%$ belonging to the authors, which highlights $16.7 \%$ of difference in scientific writing distributed in each of the areas defined above.
\end{abstract}

\section{Keywords}

Articles, science, teaching, writing, research, woman 


\section{Introducción}

A lo largo de la historia, la lucha de la mujer ha ganado un espacio importante en la construcción de una sociedad más equitativa. Parte de aquello es haber logrado la visibilización de su presencia y trabajo en el campo científico, puesto que "las mujeres han contribuido a la actividad científica desde sus orígenes, enfrentado numerosas barreras, y muy a menudo sin que se les reconozcan sus importantes aportes en esta rama de la actividad humana" (Gervasoni, 2018, 71). La sociedad intentaba mantenerla recluida bajo determinados preceptos que, de forma violenta, limitaban sus derechos porque para intereses primarios de un machismo evidente, aquello era lo correcto. "Históricamente, el papel de la mujer ha sido relegado al ámbito privado de la organización social, subestimando su capacidad de investigación. [...] dificultando el acceso de estas a la educación, que prepara para el posterior acceso al ámbito científico" (Agudo, 2006, 15). Se intentó sembrar la idea de que la mujer debía realizar actividades que no requieren de pensar mucho, como los quehaceres domésticos y la crianza de los hijos, a ello se direccionaba su educación. "Su papel se circunscribió al hogar, espacio que tampoco llegó a controlar porque, en última instancia, era dominado por quien tenía el poder económico, es decir, el hombre" (Varela, 2012, 41). La subordinación del sexo femenino se apoya, además, en disciplinas como la biomedicina que "se convierte en el enclave explicativo del estatus de las mujeres: durante mucho tiempo mujer era biología y ello en el más subordinante de los sentidos. La biomedicina se alimentaba del discurso patriarcal-occidental..." (Sánchez, 2001, 297). Es evidente que, tanto desde el enfoque cultural como desde el biológico, se intenta categorizar a la mujer como un ser útil para algún propósito, de tal modo que se minimizan sus derechos, libertades de ser humano y su autonomía; debido a ello diversos grupos y movimientos feministas que realizan análisis (en congresos, libros, etc.) sobre los cambios que se dan respecto a la situación de las mujeres promueven ideas como:

Inclusive, se insistió en que, si hace miles de años las diferencias biológicas, en especial la que se refiere a la maternidad, pudieron haber sido la causa de la división sexual del trabajo que permitió la dominación de un sexo sobre otro al establecer una repartición de ciertas tareas y funciones sociales, hoy esto ya no tiene vigencia (Lamas, 2011, 29).

Desde tiempos inmemoriales, el humano tuvo curiosidad por descubrir su origen, así como los misterios del lugar donde se desenvuelve y convive junto al mundo animal, vegetal y mineral. Logró esclarecer incógnitas y descubrir procesos de la naturaleza gracias a la ciencia, definida como una "historia de millares de personas que contribuyeron al conocimiento y a las teorías que constituían la ciencia de su época, haciendo posibles los 'grandes saltos'. Muchas de esas personas fueron mujeres. $Y$, sin embargo, su historia sigue siendo virtualmente desconocida" (Alic, 2005, 13).

La discriminación hacia la mujer no es connatural a la humanidad, como lo expone la investigadora Dolores Ayllón (s. f.) en su trabajo titulado "Las mujeres en la prehistoria y la historia antigua" que demuestra la existencia de una sociedad igualitaria en aquellas épocas; durante el período paleolítico, en las sociedades primitivas no existía la división del trabajo, las mujeres compartían actividades como caza, pesca, recolección de alimento y otros trabajos con los hombres. Las mujeres aportaron al desarrollo humano en el aspecto cultural porque se encargaban de la educación, del cuidado infantil, de la medicina, eran sacerdotisas, no sufrían discriminación ya que en la prehistoria 
regía el matriarcado. En el período neolítico, continuó con su aporte por ser creadora de actividades como la agricultura, la conservación de alimentos, la farmacología, el uso de minerales, la cerámica, la curtiembre, el tejido, las artesanías, las herramientas, entre otros (Ayllón, D., s. f.).

Se podría concluir que desde tiempos antiguos las mujeres aportaban al desarro- llo y bienestar de sus contextos sociales, y así determinar la discriminación como una construcción cultural. Es de conocimiento general que en las civilizaciones antiguas comienzan a marcarse las diferencias entre atribuciones de hombres y de mujeres, como se resume en la tabla 1 , realizada a partir del trabajo de Dolores Ayllón (s. f.), ya mencionado.

Tabla 1. Diferencias de los derechos y libertades de la mujer en las antiguas civilizaciones

\begin{tabular}{|c|c|c|c|c|}
\hline Aspectos & Mesopotamia & Egipto & Grecia & Roma \\
\hline En general & $\begin{array}{l}\text { La situación de la } \\
\text { mujer determina } \\
\text { la clase social y } \\
\text { ciudad. }\end{array}$ & $\begin{array}{l}\text { Libre e independiente, } \\
\text { alcanzó las más altas } \\
\text { esferas de poder. }\end{array}$ & Espacio privado y doméstico. & $\begin{array}{l}\text { Dependían de sus } \\
\text { maridos. }\end{array}$ \\
\hline Derechos & $\begin{array}{l}\text { Desiguales entre } \\
\text { hombres y mujeres }\end{array}$ & $\begin{array}{l}\text { Igualdad de derechos. } \\
\text { Gran importancia } \\
\text { sociopolítica. }\end{array}$ & $\begin{array}{l}\text { Ninguno. } \\
\text { Era común el abandono de } \\
\text { niñas por falta de dote. }\end{array}$ & $\begin{array}{l}\text { Derecho de sucesión } \\
\text { respecto al padre. } \\
\text { Las viudas o huérfa- } \\
\text { nas adquirían todos } \\
\text { los derechos. }\end{array}$ \\
\hline Matrimonio & $\begin{array}{l}\text { Acordado por el } \\
\text { padre o hermano. } \\
\text { Recibía dote. }\end{array}$ & $\begin{array}{l}\text { Desde solteras goza- } \\
\text { ban de autonomía jurí- } \\
\text { dica, luego de liberada } \\
\text { para elegir esposo. }\end{array}$ & $\begin{array}{l}\text { Contrato entre el padre y el } \\
\text { futuro esposo. } \\
\text { Había la dote. }\end{array}$ & $\begin{array}{l}\text { Concertado por el } \\
\text { padre de la novia. } \\
\text { Aportación de la dote. } \\
\text { Cuando la mujer era } \\
\text { más adinerada desco- } \\
\text { nocía la autoridad del } \\
\text { marido. }\end{array}$ \\
\hline Divorcio & & $\begin{array}{l}\text { No sufría perjuicio en } \\
\text { caso de divorcio } \\
\text { Si enviudaba, heredaba } \\
\text { todo. }\end{array}$ & $\begin{array}{l}\text { Solo el padre podía pedir } \\
\text { divorcio. Las atenienses sí } \\
\text { podían pedir divorcio. }\end{array}$ & $\begin{array}{l}\text { Ella perdía la tutela de } \\
\text { los hijos. } \\
\text { El marido devolvía la } \\
\text { dote. }\end{array}$ \\
\hline Libertades & $\begin{array}{l}\text { Hacer transaccio- } \\
\text { nes comerciales } \\
\text { por sí mismas. } \\
\text { Participar en la vida } \\
\text { pública. } \\
\text { Firmar } \\
\text { documentos. }\end{array}$ & $\begin{array}{l}\text { Todas las libertades. } \\
\text { Comenzó a perder sus } \\
\text { libertades y derechos } \\
\text { a finales del siglo III de } \\
\text { nuestra era. }\end{array}$ & $\begin{array}{l}\text { El hogar y los niños } \\
\text { Clase alta: confinadas a la } \\
\text { habitación de mujeres. } \\
\text { Clase baja: venta de produc- } \\
\text { tos agrícolas y artesanales. }\end{array}$ & $\begin{array}{l}\text { Tenían derecho a la } \\
\text { recreación. } \\
\text { Las de clase alta } \\
\text { tenían esclavos. } \\
\text { Las de clase baja } \\
\text { servían al resto. }\end{array}$ \\
\hline $\begin{array}{l}\text { Educación y } \\
\text { profesiones }\end{array}$ & $\begin{array}{l}\text { Las de clase alta: } \\
\text { Eran alfabetizadas } \\
\text { Sacerdotisas } \\
\text { Ejercían autoridad } \\
\text { administrativa } \\
\text { Escribas } \\
\text { Médicas }\end{array}$ & $\begin{array}{l}\text { Visires, juezas, } \\
\text { médicas, funciona- } \\
\text { rias, empresarias, } \\
\text { sacerdotisas, tenían } \\
\text { propiedades rurales, } \\
\text { comadronas, masa- } \\
\text { jistas, perfumistas, } \\
\text { hilanderas. } \\
\text { Profesiones vedadas: } \\
\text { ejército, tallar piedra, } \\
\text { albañilería }\end{array}$ & $\begin{array}{l}\text { No tenían educación formal. } \\
\text { Eran analfabetas. } \\
\text { Aprendían de su círculo } \\
\text { cercano. Papeles: esposa, } \\
\text { concubina, prostituta, } \\
\text { cortesana. } \\
\text { En Esparta tenían educa- } \\
\text { ción, eran ciudadanas con } \\
\text { derechos de hacer deporte y } \\
\text { música, y tenían esclavas. }\end{array}$ & $\begin{array}{l}\text { Las mujeres te- } \\
\text { nían acceso a la } \\
\text { educación. }\end{array}$ \\
\hline
\end{tabular}


La lectura de la tabla invita a pensar que las sociedades más recientes son las que otorgaron menos derechos y libertades a las mujeres en tanto que la cultura egipcia fue completamente justa. Es destacable que las reglas sociales de la Antigua Roma restringen más las libertades femeninas, así, es oportuno agregar el hecho de que el mundo occidental desciende culturalmente de la civilización romana. Nuevamente, cabe anotar la reflexión de que la diferencia desproporcionada (favorable a los hombres), en cuanto al trato y consideración de la mujer como ser libre, intelectual y capaz de ejercer sus derechos y libertades, nace de un modo subjetivo en las prácticas culturales.

\begin{abstract}
Diversas ciencias sociales y campos del conocimiento afines a las humanidades han tomado las perspectivas revisionistas y las incluyeron en sus investigaciones. Este fue el caso de la arqueología, en donde las escuelas norteamericanas y escandinavas fueron pioneras en incluir que el discurso presentista había configurado, bajo prismas androcéntricos y patriarcales, una representación del objeto de estudio meramente masculino, en donde las mujeres no presentaban un papel activo en el desarrollo de la humanidad (Marín, 2020, 8).
\end{abstract}

Lo antes mencionado podría ajustarse a la lógica de que la ciencia, por ser una construcción humana, también lo es cultural, por tal motivo se convirtió en un mundo masculino y sus puertas se abrieron a las mujeres en contadas ocasiones, hecho similar al que "las diferencias entre mujeres y hombres obedecen a esa interpretación y subjetivación cultural" (Guzmán, 2016, 12). A ello se suma la visión filosófica, pues "desde la filosofía clásica, la diferencia ontológica entre el alma y el cuerpo ha significado apropiaciones culturales respecto al sexo, siendo la mente relacionada a lo masculino y el cuerpo a lo femenino" (Vargas, Lutz, Apuzinski y Arancibia, 2020, 3). Estas orientaciones de predilección varonil repercuten en la sociedad actual como demuestra, entre otras manifestaciones, el modo de escribir; por ejemplo, se utiliza la palabra hombre para referirse quienes escriben (mujeres $u$ hombres), como en este caso: "El texto científico es un reflejo de la actividad cognoscitiva del hombre y del progreso de la ciencia y la tecnología..." (Padrón, Quesada, Pérez, González y Martínez, 2014, 77).

Se han reformulado nuevas hipótesis y teorías e ideado nuevas metodologías para abordar disciplinas como la historia, la antropología, la filosofía la sociología, etc. También se han sacado a la luz y evaluado las metáforas utilizadas, pero también los sesgos metodológicos y androcéntricos en la elaboración de dichas hipótesis o en las prácticas científico-tecnológicas, no solo en humanidades y en ciencias sociales (Pérez, 2018, 24).

El aporte de las mujeres a la ciencia conlleva el hecho de que plasmen sus conocimientos en la escritura, sin embargo, en tiempos pasados no era común que las mujeres realicen escritos científicos; en general, "las que escribían" lo hacían como hija, hermana o esposa de un hombre, con la posibilidad inminente de que aún ellas mismas no quieran publicar sus nombres, mientras que los hombres escribían identificándose abiertamente y sin prejuicio.

Esto sucedía no solo en la ciencia sino también en lo poético, tal es el caso de la colombiana Agripina Samper (1831-1894); su hermano "José María Samper, en sus memorias Historia de un alma afirma que su padre no veía con buenos ojos la actividad intelectual de su hermana" (Alzate, 2017, 10). Otro ejemplo es la francesa Amandine Aurore Lucie Dupin (1804-1876), quien adoptó el seudónimo de George Sand "por consejo del editor" (Castañón, 2013, 134), su escritura se marcó "por sus ideales sociales y humanitarios" (Peiró, 2018, 18).

Históricamente la mujer intervino, además, en la esfera política; ejemplo de 
ello es Manuela Sáenz, quien participó en las luchas libertarias de América del Sur, sin la aprobación familiar. Su aporte ideológico, político y económico fue perentorio para la lucha por la liberación del dominio español de aquel pasado, sin embargo "la dificultad es que promover a la Manuela política, [...] implica bajar al Libertador de su pedestal, igualarlo a ella y minar, por lo tanto, la fundación del poder patriarcal nacional" (Lander, 2011, 169). Una vez más se dilucida la preponderancia del papel masculino en la toma de decisiones, según las circunstancias y acorde al objetivo que se persiga en cada uno de los ámbitos.

Con el pasar de los años, la situación de la mujer ha cambiado, no obstante, existen evidencias de que hoy la sociedad aún no acepta que las mujeres puedan acceder al estudio y la formación superior en igualdad de condiciones que los hombres, como se evidencia en algunas investigaciones. Se realizó una investigación basada en entrevistas a estudiantes feministas, quienes denunciaron episodios de violencia contra mujeres. Entre las conclusiones de la investigación se manifiesta que la "presencia que todavía tiene hoy el sexismo en la UNAM nos habla de que, a pesar del paso del tiempo, aún queda un largo camino por recorrer para que el hecho de ser mujer no suponga una carga..." (Mingo, 2020, 27). Pese al logro en el alcance de varios derechos, las desigualdades aún se marcan, lo que provoca en la mujer el desarrollo limitado de su potencial en el terreno científico. Pues, "las mujeres han demostrado con creces lo infundado de las creencias sobre su falta de talento" (Guil, 2016, 37). Es relevante destacar la participación femenina en la escritura de artículos científicos, como aporte a la universidad y alcance de una conquista en lo académico.

Otro punto importante es la participación activa del grupo "Científicas de Acá" de Argentina como un proyecto que visibiliza el trabajo que hacen las mujeres investigadoras en ciencia y tecnología, dan a conocer al mundo el trabajo realizado por cada una de ellas en el aspecto científico.

Los sitios más consultados en la web para datos biográficos, como Wikipedia, muestran desbalances de género muy marcados: de cada 10 artículos sobre cientificxs argentinxs [sic], isolo 2 corresponden a mujeres! Sitios de acceso y edición libre como la Wikipedia reproducen los sesgos que existen en la sociedad. Si no conocemos a las científicas, no escribimos sobre su vida. Si no leemos sobre ellas, ¿cómo las vamos a reconocer?

Científicas de Acá busca ser una acción directa para reconocer el trabajo científico de las mujeres de Argentina y Latinoamérica. (Científicas de acá.com)

En el caso del Ecuador, el Centro Internacional de Estudios Superiores de Comunicación para América Latina (CIESPAL) realiza cada año el Congreso de Mujeres Científicas, al cual asisten científicas contemporáneas, tanto participantes como ponentes, de Iberoamérica y de otras latitudes.

\section{Metodología}

Por ser un estudio que utilizó datos estadísticos se aplicó la metodología cuantitativa, gracias a ello se estableció la cantidad de artículos escritos por hombres y mujeres; lo que evidenció estadísticamente la relevancia que se da a la escritura científica enmarcada por el género cuando se trata de investigación como contribución social.

Los datos fueron tomados de las revistas publicadas por las diferentes facultades de la Universidad Central, en las que se propende a mejorar la publicación de acuerdo con los requerimientos establecidos por las entidades de control de calidad de escritura científica. Se consideró únicamente aquellas revistas que se encontraban presentes en el 
"Portal de Revistas UCE", hasta junio de 2019. El período para la toma de datos se dividió en dos etapas 2014-2018 y 2016-2018, bajo el manejo de recolección de información determinado en la técnica cuantitativa con la finalidad de manejar un proceso sistemático de construcción estadístico comparativo.

Las estadísticas usadas para el estudio son: nombre de la revista, facultad, año, autor interno -son parte de la Universidad Central- o externo -pertenecen a otras instituciones- los que se dividieron en categoría hombres y categoría mujeres, además de las tres áreas del conocimiento que son:
"Ciencias de la Vida y Salud, Ciencias Exactas y Ciencias Sociales" (Estrella, 2016, 5).

Los datos arrojaron un total de 42 revistas, con 590 artículos escritos por 1536 autores internos y externos.

\section{Resultados}

Se observó que a partir de 2014 existe una mayor tendencia en la categoría hombres, lo que hace notar que en este período la batuta de la escritura científica se marca por la presencia mayoritaria de este género, como se podrá observar en los cuadros y gráficos que se presentan a continuación:

Figura 1. Artículos científicos 2014-2018 (389 artículos / 841 autores)

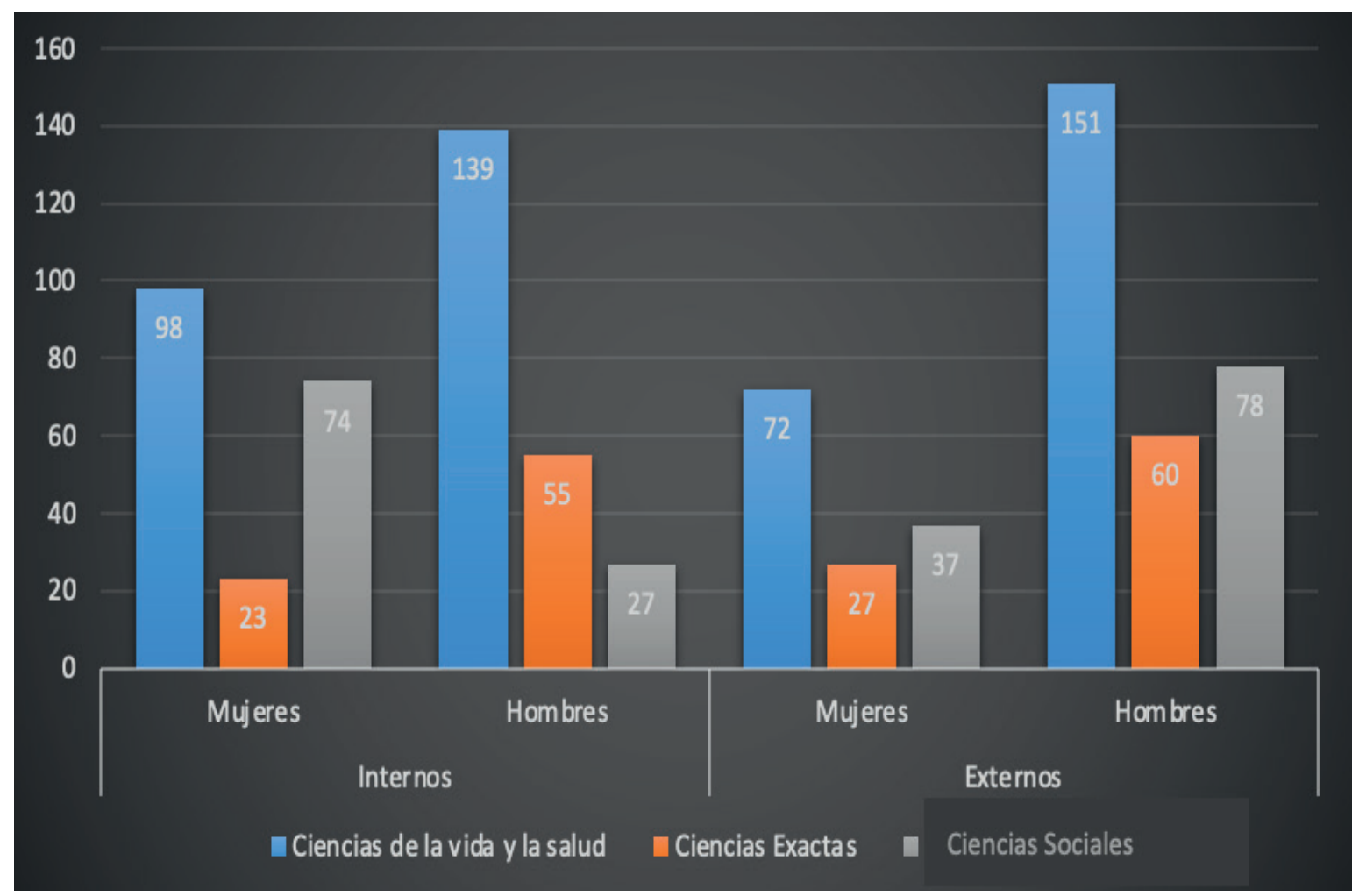

En la figura 1, que corresponde al período 2014-2018 se observa que existe mayor escritura científica por parte de los autores externos, especialmente hombres, en las revistas que corresponden al ámbito Ciencias de la Vida y Salud, haciendo hincapié en la revista de la Facultad de Ciencias Médicas; a diferencia de las mujeres, como autoras internas. Se va marcando la tendencia de dos autores por artículo, en promedio. 
Se puede notar menor interés por el ámbito de las Ciencias Exactas por parte de las mujeres, tanto internas como externas, a diferencia de los hombres, que doblan en nivel de interés. En el caso de los autores internos, son 55 hombres, mientras que las mujeres son 23, al igual que en los externos, 60 hombres frente a 27 mujeres.

Figura 2. Artículos científicos 2016-2018 (201 artículos / 585 autores)

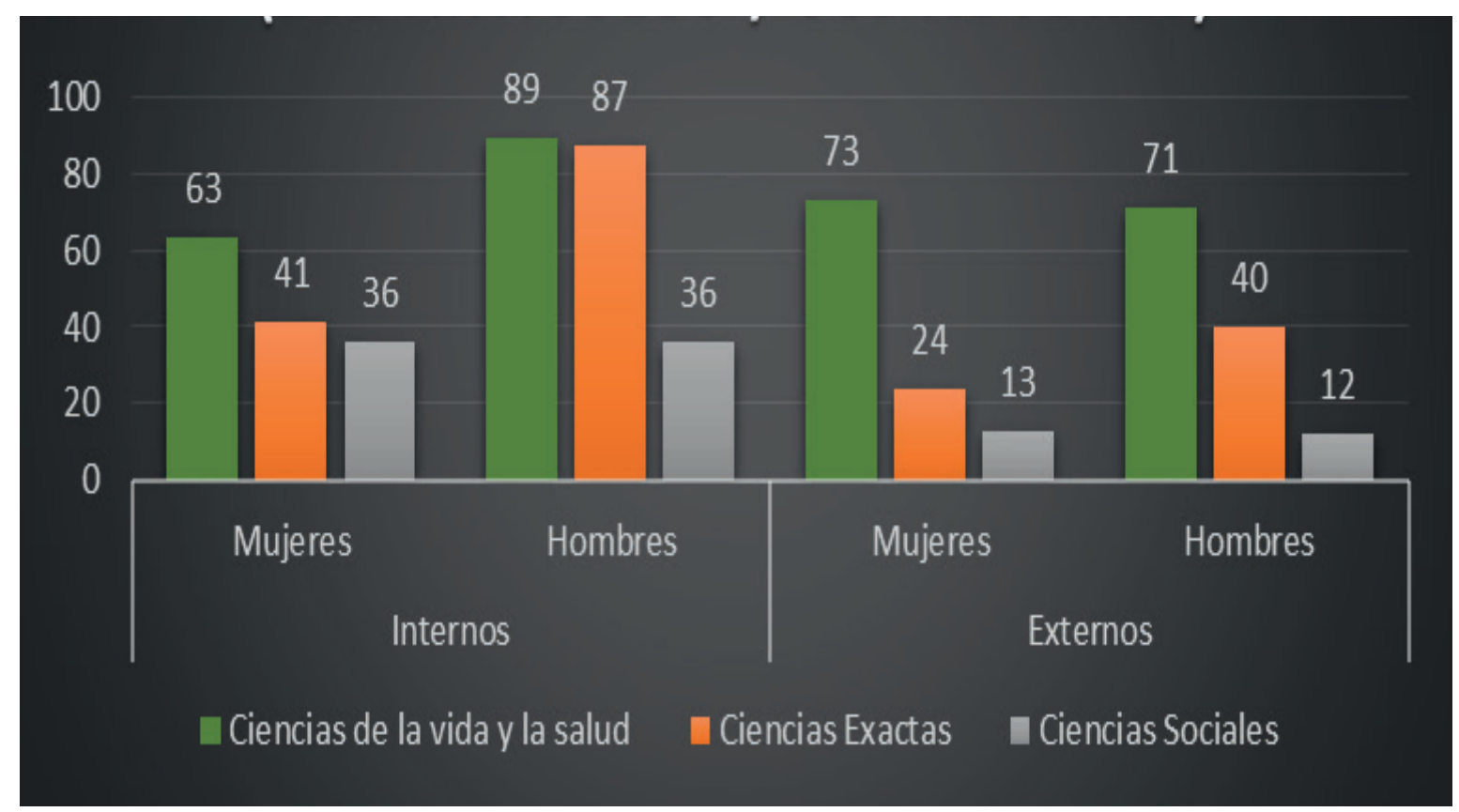

En la figura 2, que corresponde al período 2016-2018 se observa que existe mayor número de autores internos, sobre todo se enmarca en Ciencias de la Vida y Salud y Ciencias Exactas, haciendo notar una fuerte caída en los artículos científicos dentro del ámbito de las Ciencias Sociales, esto se debe a que los autores y autoras, como docentes de la universidad, entraron en el proceso de recategorización y la escritura científica es el eje fundamental para aquello.

En relación con los externos, la preferencia continúa marcada por Ciencias de la
Vida y Salud, destacándose mayor número de publicaciones en las revistas Odontología (Facultad de Odontología) y Siembra (Facultad de Agronomía). El promedio por autores de artículo llega a tres.

En este período, 2016-2018, la revista que repunta es Figempa, de la Facultad de Ingeniería en Geología, Minas, Petróleos y Ambiental.

Con respecto a la presencia de las mujeres, como autoras de artículos científicos, tienen mayor presencia las externas, en el área de Ciencias de la Vida y Salud. 


\section{Análisis por área de conocimiento y por año}

Período 2014-2018

Figura 3. Internos y externos. Ciencias de la Vida
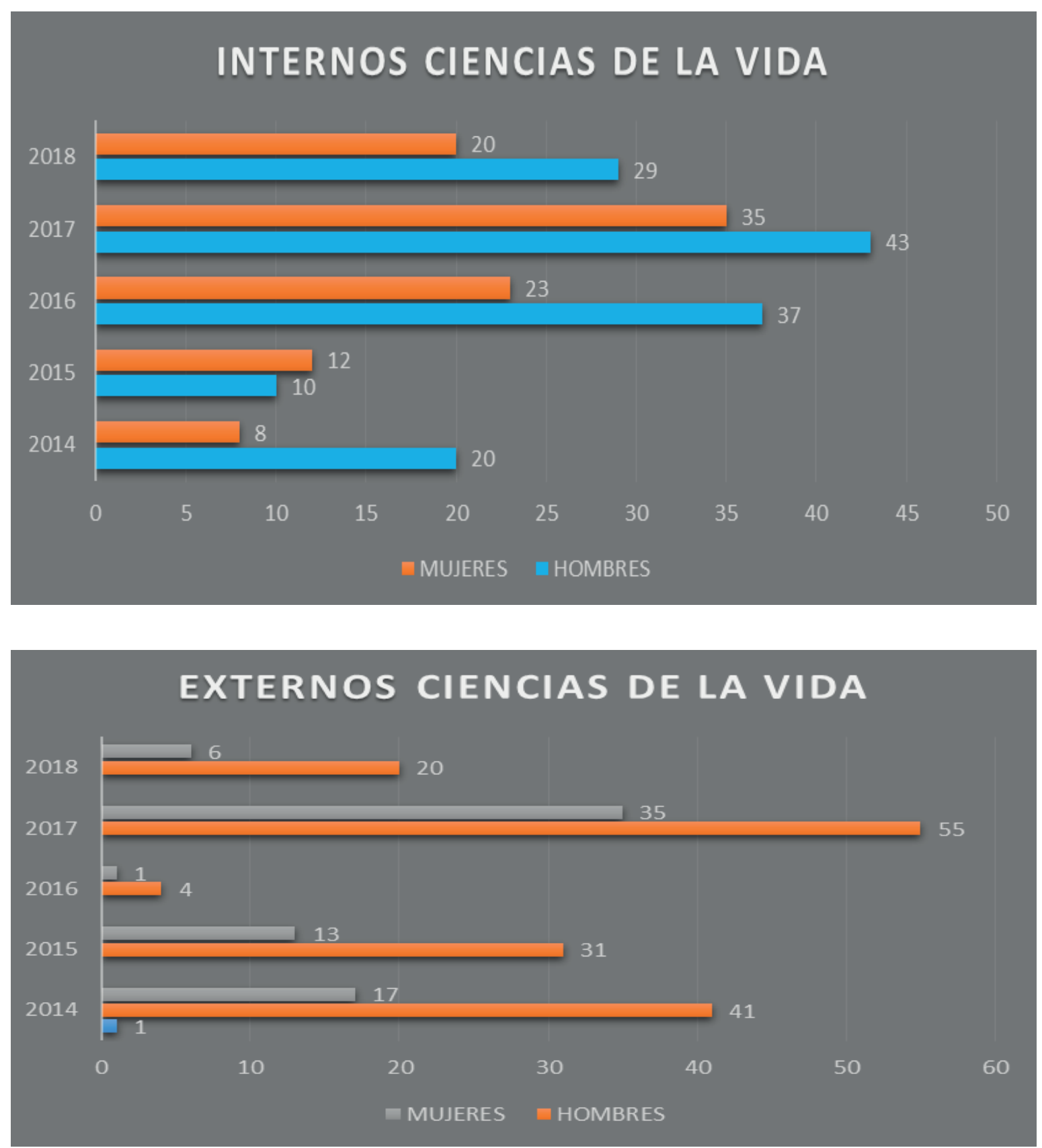

En la figura 3, se observa un comparativo entre autores internos y externos, en el área Ciencias de la Vida y Salud. El año que cuenta con mayor aporte de producción científica, tanto interna como externa, es 2017. De igual manera, se observa una mar- 
cada diferencia entre autoras y autores, la producción de las primeras es de 70, mientras que de los hombres es 98, es decir, el $41.6 \%$ que corresponde a las mujeres, y el $58.3 \%$, a los hombres, lo que demuestra que, la brecha es del $16.7 \%$, lo que hace notar que la mujer como autora de artícu- los científicos aún mantiene un margen de distancia con los hombres, esto denota la baja participación en actividades de investigación científica para el año ya mencionado. Es menester recordar que, en 2017 ya se notaba la presencia de la mujer en la investigación, su participación crece a un ritmo lento.

Figura 4. Internos y externos. Ciencias Exactas

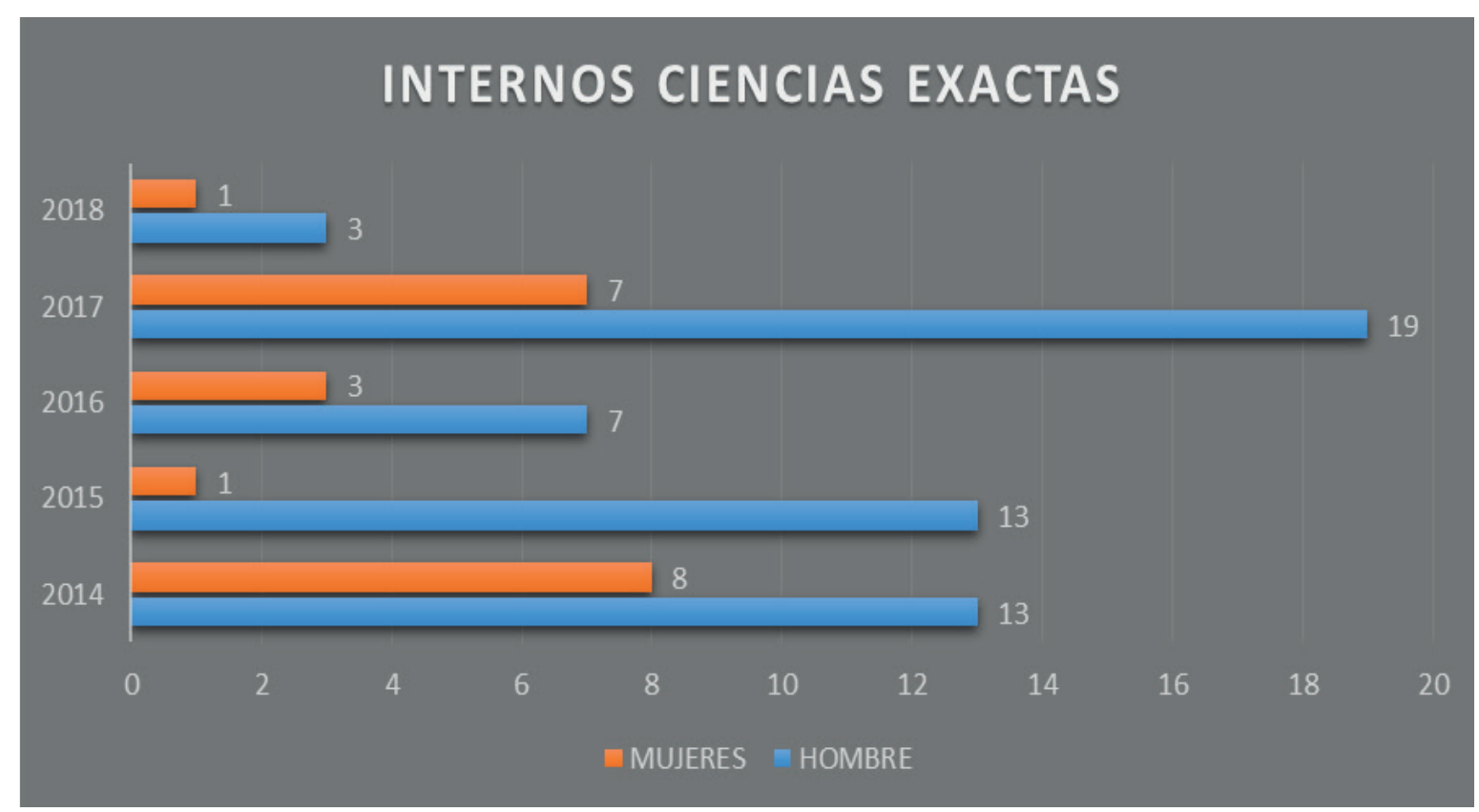

\section{EXTERNOS CIENCIAS EXACTAS}

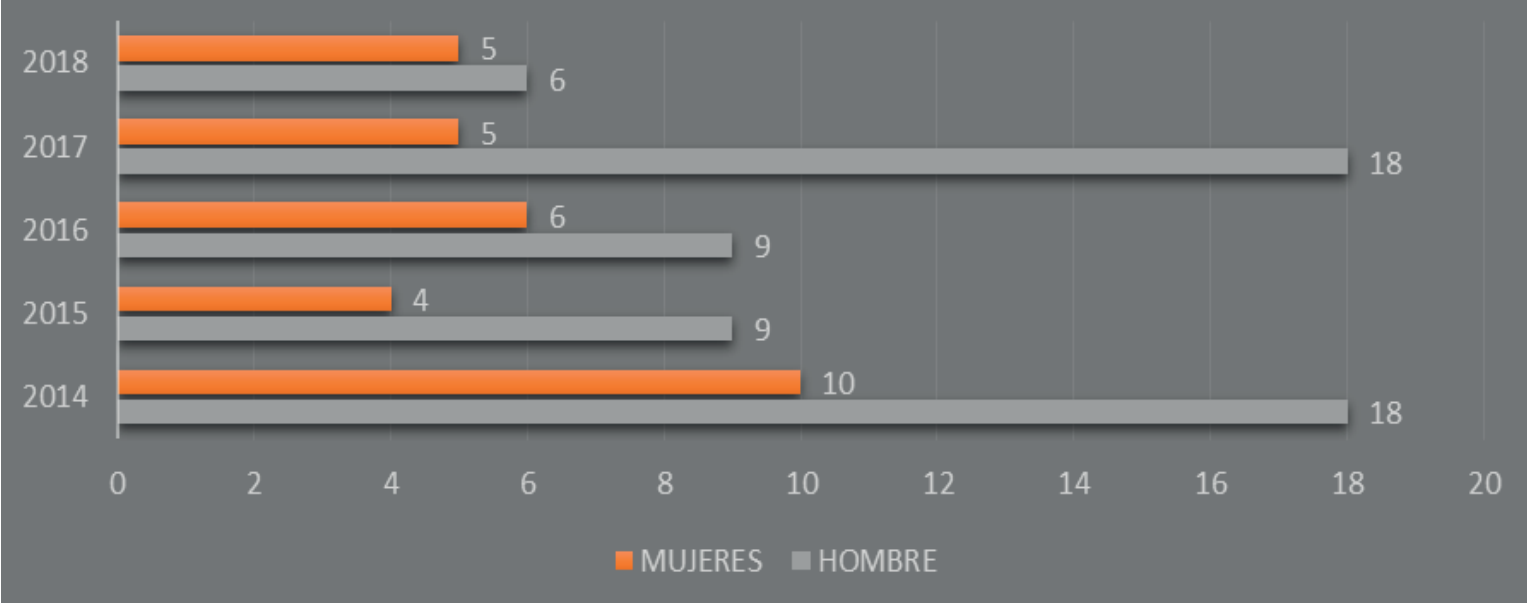


En la figura 4 se realizó una comparación entre internos y externos; el año más destacado, en la creación de artículos científicos en el área de las Ciencias Exactas fue 2017, con un total de 49 autores, de los cuales el 53 \% responde a la producción interna; mientras que el $46.93 \%$ es de los externos; destacándose una vez más los autores masculinos, con un total de 37 y 12 mujeres.

En 2016 existe una caída de la investigación, con 23 autores; un $69.56 \%$ de autores, tanto internos como externos, son hombres (16 en total); y 7 mujeres, que corresponden al $30.43 \%$.

Figura 5. Internos y externos. Ciencias Sociales
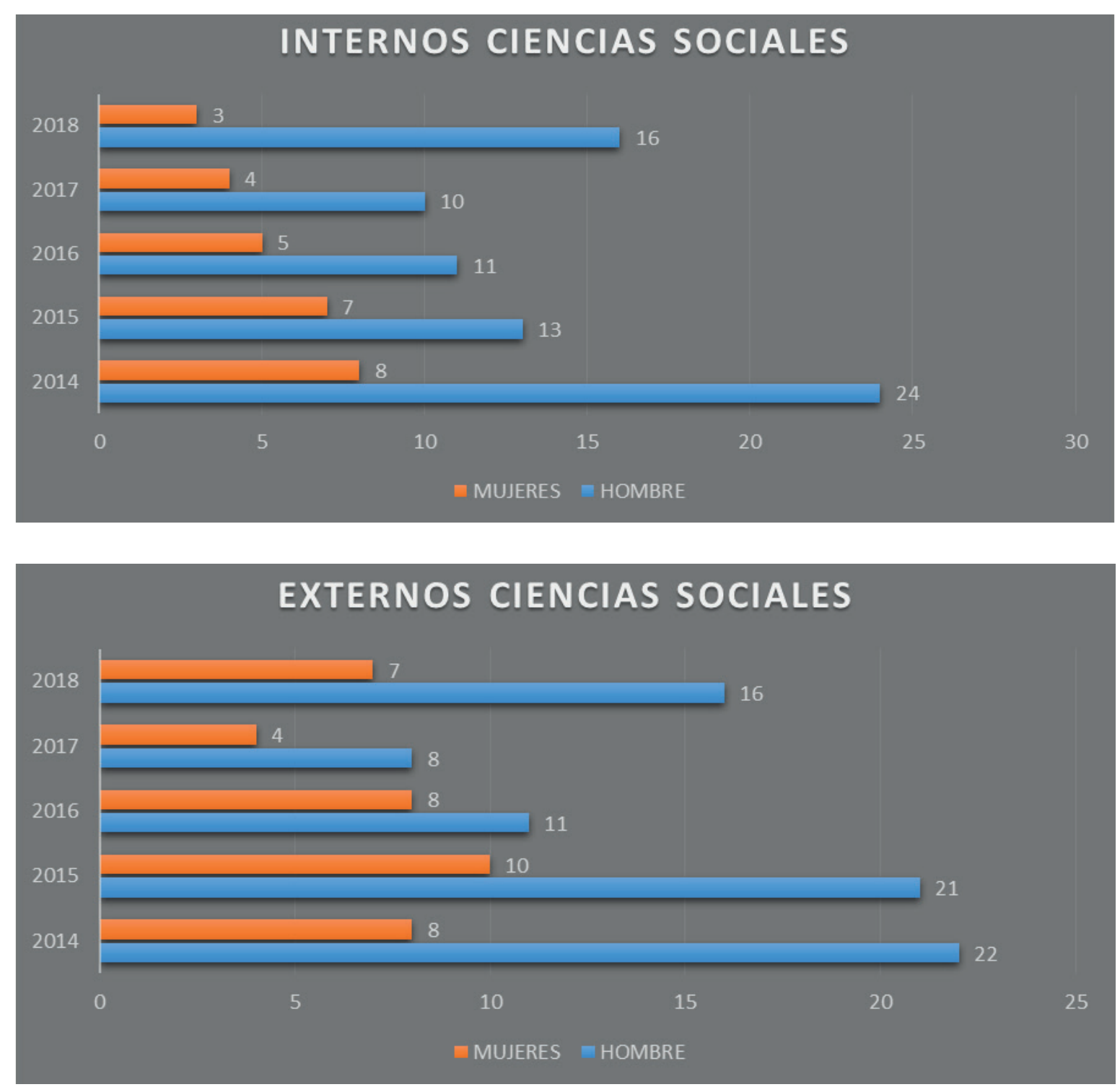

En lo que se refiere al área de Ciencias Sociales, destaca el año 2014, con 30 autores externos y 32 internos, se observa que se presenta una caída de la escritura científica en 2017; internos 14 y externos 12.
En cuanto a la categoría mujeres, internas y externas, el número se mantiene, siendo bajo en relación con la participación de la mujer dentro del aspecto científico. 
Figura 6. Internos y externos. Ciencias de la Vida

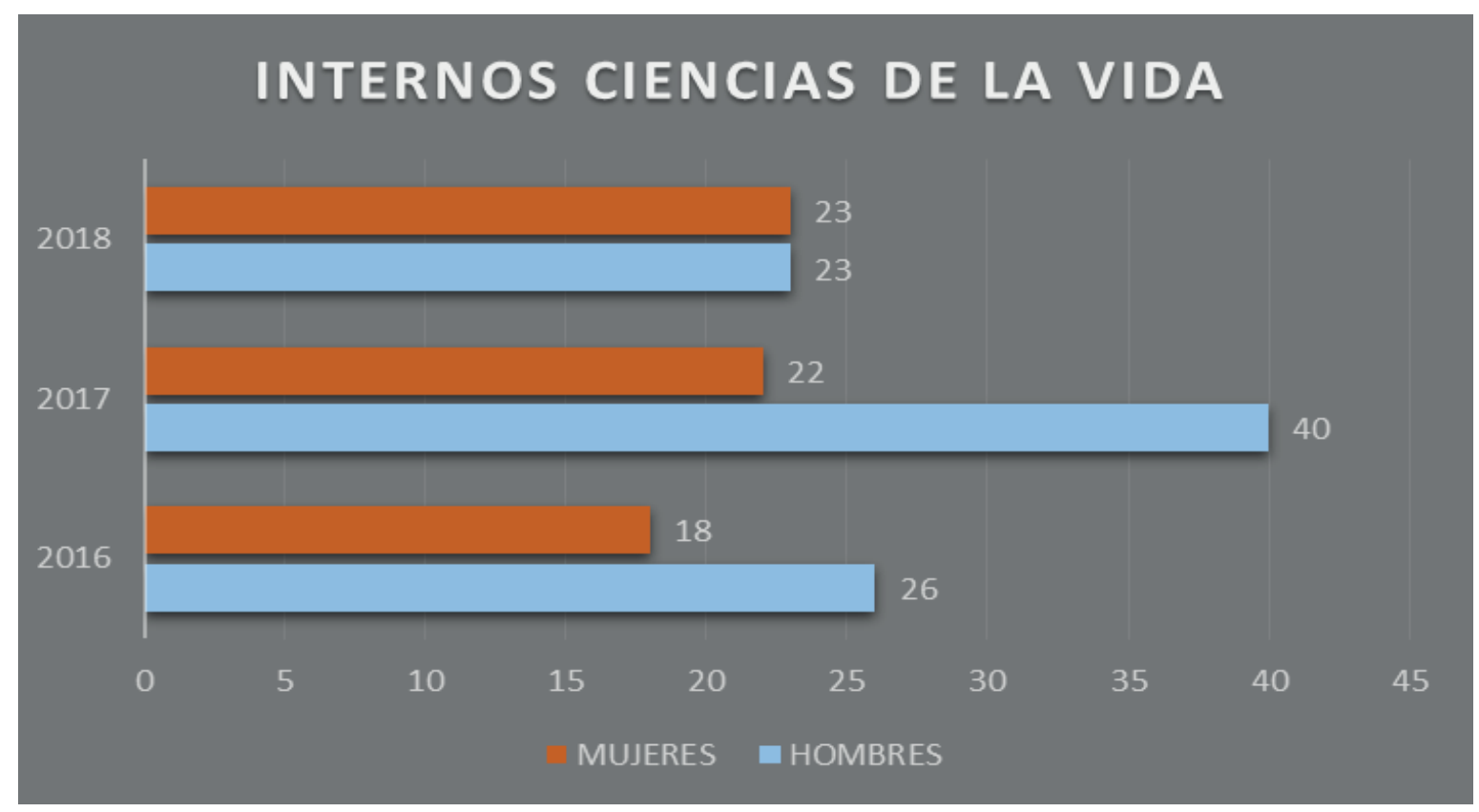

\section{EXTERNOS CIENCIAS DE LA VIDA}

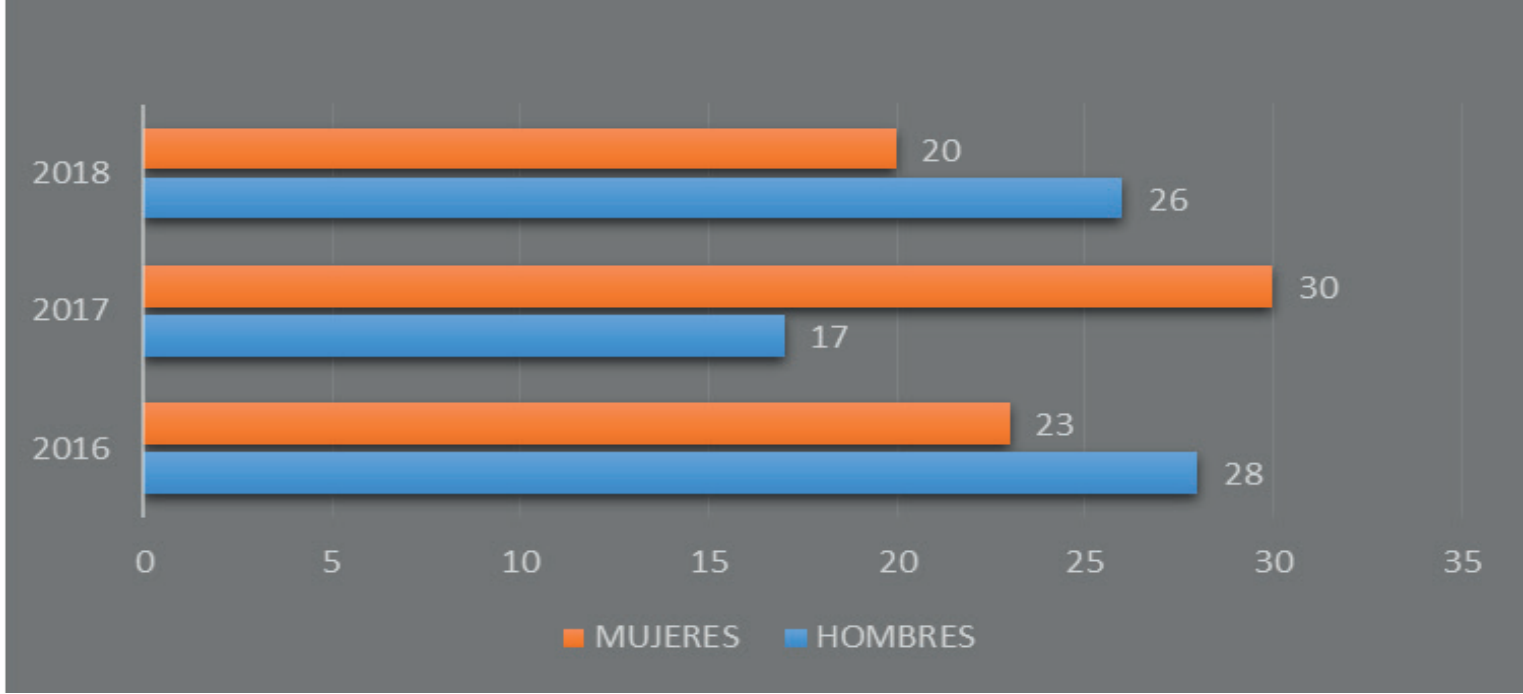

Se nota que durante el 2017 escribieron un total de 62 autores entre hombres y mujeres (internos) y 30 mujeres externas lo que nos lleva a pensar que la mujer toma parte activa en la escritura científica con la finalidad de generar aporte a la universidad como tal y al estado, esto con relación a la responsabilidad que tienen los centros de educación superior con la sociedad. 
Figura 7. Internos y externos en Ciencias Exactas
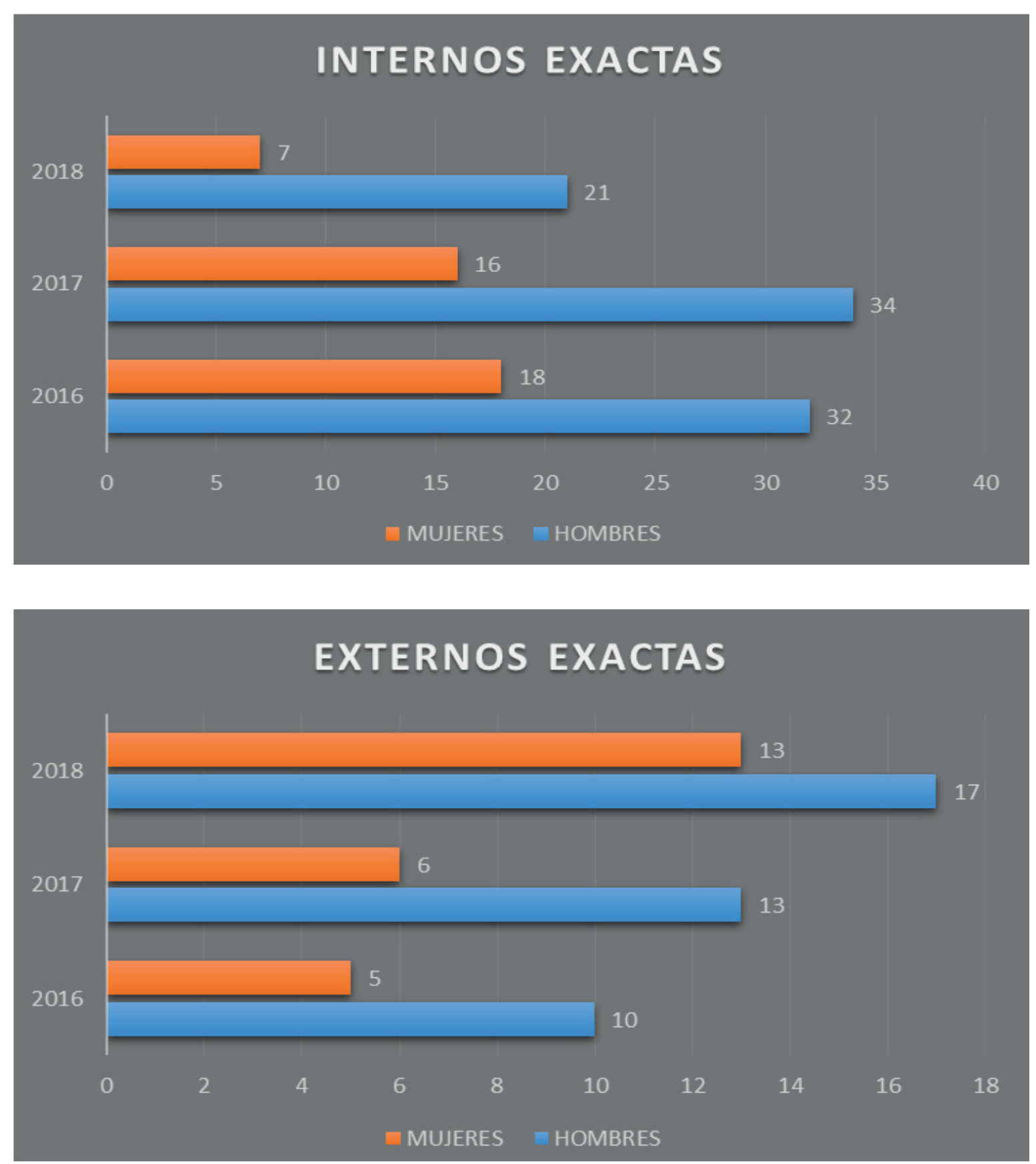

En la primera parte de la figura 7 se puede observar que la cantidad de artículos que se produjo por autores internos fue igual entre 2017 y 2018. Es decir, en 2017 el 68 \% corresponde a los autores hombres, mientras que $32 \%$ es la participación interna de mujeres. Para 2018 la participación crece en un $2 \%$ adicional para las mujeres.
En la segunda parte de la gráfica se destaca el año 2018, con una producción científica de $56.67 \%$ hombres (17) y 43.33 $\%$ mujeres (13), por lo que la brecha entre las dos categorías cada vez se vuelve menor; es decir, se hace notar ya la presencia de la mujer en la investigación. 
Figura 8. Diferencia de escritura cientifica, área ciencias sociales
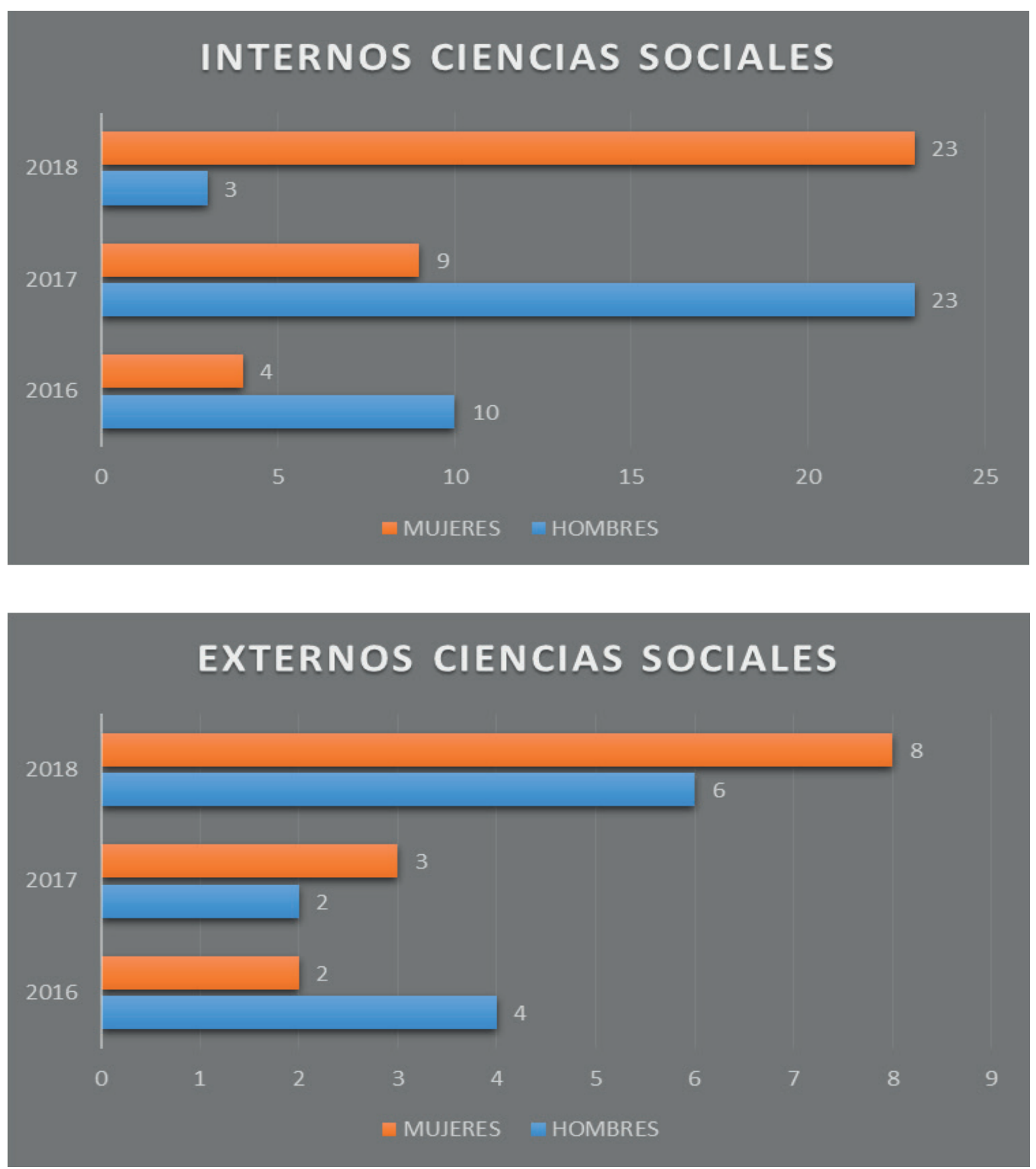

En la gráfica anterior se puede observar con notoriedad que la escritura científica va marcando una diferencia en la UCE, entre autores hombres y mujeres, especialmente en el área de las Ciencias Sociales, pasando los hombres de un $79 \%$ en 2017 a un 11.54 $\%$ en 2018; lo que determina que la presen- cia de la mujer es mayor con respecto a los hombres.

Es así que en el año 2018 la producción científica femenina en lo social marca el $88.46 \%$; es decir, la participación de la categoría mujeres se va vinculando de forma positiva en pro de la universidad pública 
y orienta su interés fundamental en las problemáticas sociales.
En cuanto a las autoras externas prevalece la misma tónica entre el 2017 y 2018.

Figura 9. Evolución de la escritura cientifica autores hombres vs. mujeres (2 períodos)

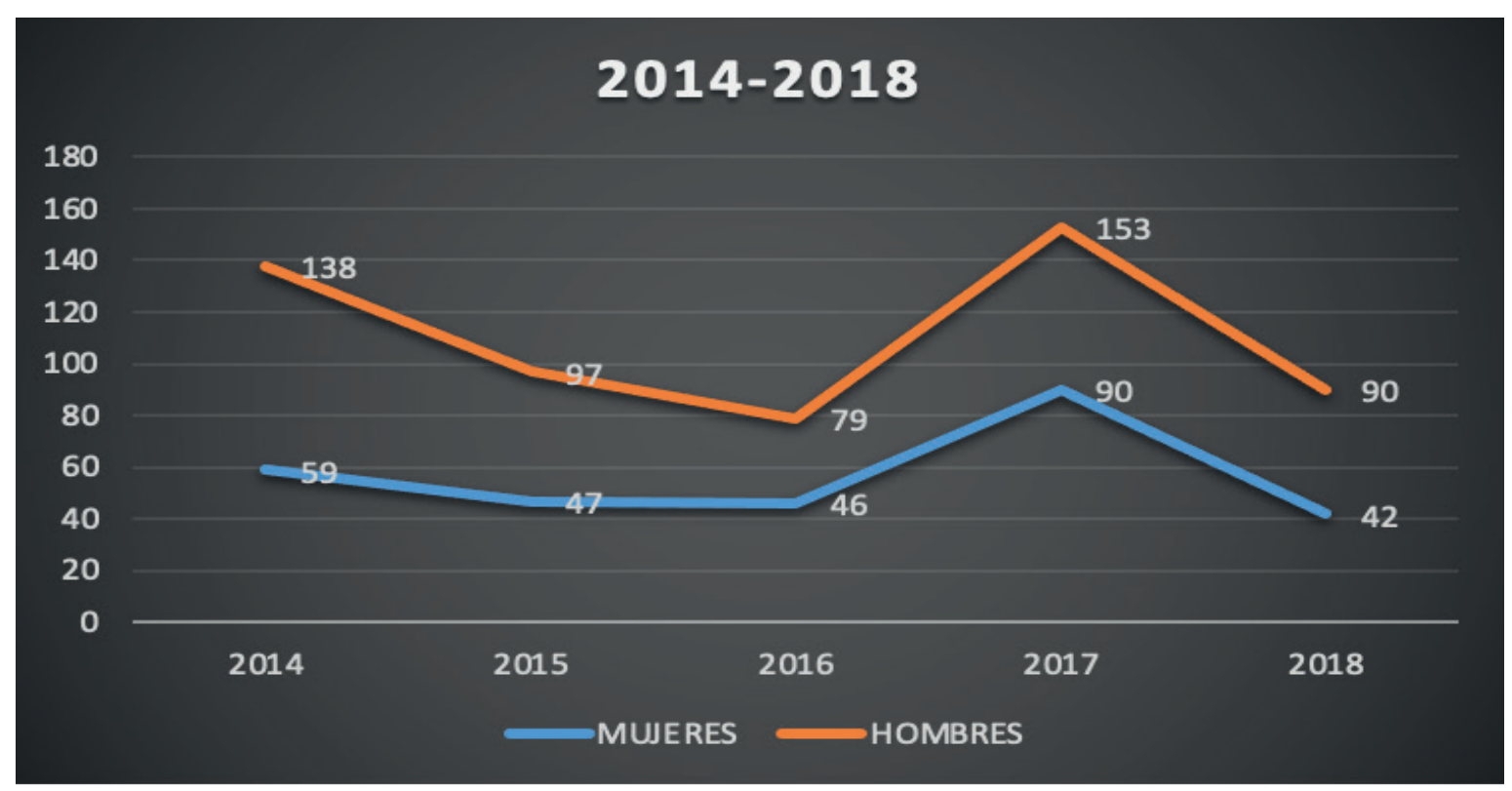

\section{6-2018}

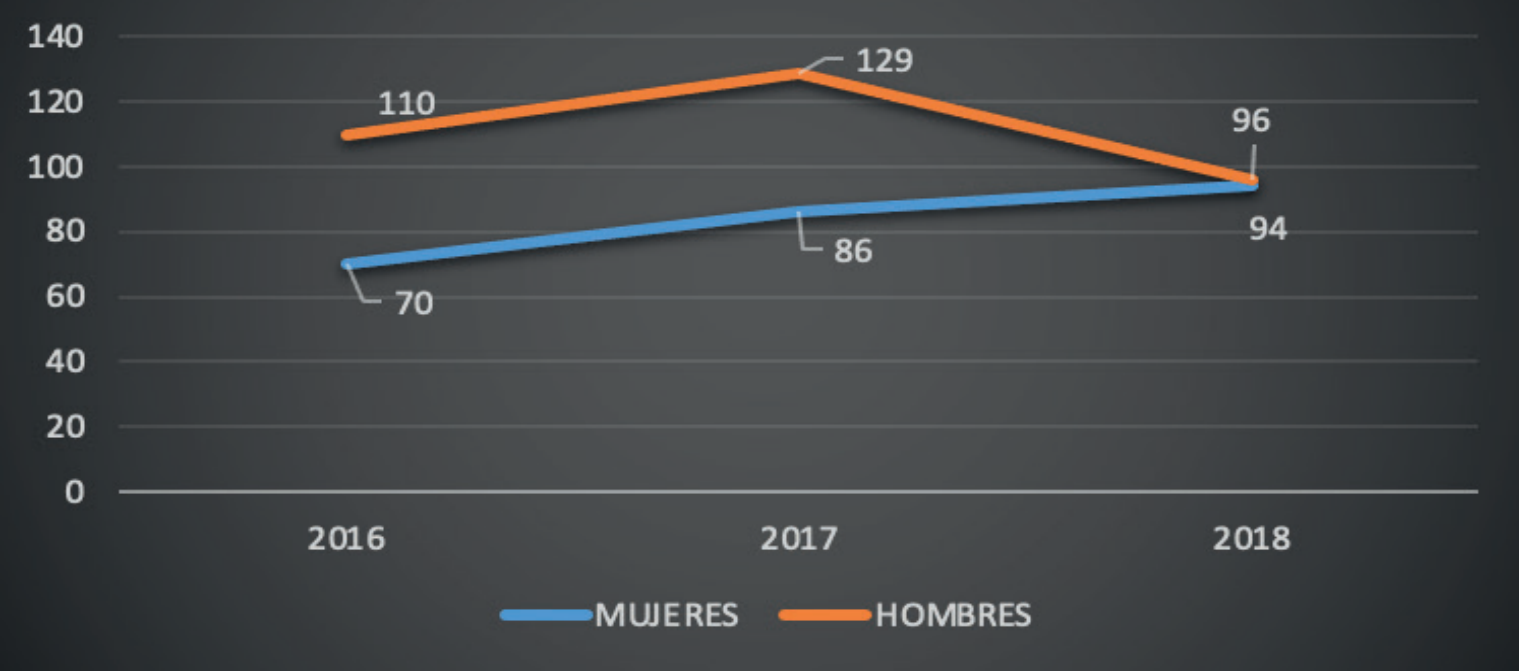

En resumen, en las dos últimas gráficas se muestra la evolución de la escritura científica por parte de las categorías hombres y mujeres internos y externos.

Para el período 2014-2018 se hace notoria la participación de los varones en la producción científica, con una caída en 2016 y un ascenso durante 2017, especialmente en lo que se refiere a las Ciencias Exactas.

Mientras que en el período 2016-2018 destaca la presencia de la categoría mujeres en el área de Investigación, pasando de 70 
autoras a 94, manteniendo así una diferencia con los hombres. Por lo tanto, realza que el ritmo de trabajo femenino en la actualidad busca ir posicionándose cada vez más en ámbitos con mayor relevancia participativa, con enfoques de equidad.

\section{Discusión}

La búsqueda permanente de la equidad de género en todos los sectores, logra que la academia no sea la excepción, pues la participación femenina en escritura científica era limitada, y quienes incurrían en dichas tareas debían hacerlo bajo la tutela de un hombre, porque supuestamente "ser mujer significa asumir un modo de estar en el mundo en el que la maternidad, los cuidados, el trabajo doméstico, la heterosexualidad y la ausencia de poder son características constitutivas del género femenino" (Cobo, 2014: 9). A medida que pasa el tiempo la mujer inserta su participación activa en la investigación, para posicionarse, paulatinamente, en lugares antes no permitidos, como la universidad.

En tiempos pasados, la jerarquía impuesta no permitía la participación de la mujer en la vida académica, espacio exclusivo de los hombres; respecto a ello se han realizado estudios, como la investigación historiográfica sobre la participación femenina en la vida universitaria, realizada por Pilar Ballarín, (2010) en España. En la mencionada investigación, luego de analizar décadas anteriores a 1980, manifiesta que "habrá que esperar a los ochenta, período en que nuestra democracia se va consolidando, crece la estabilidad de las profesoras universitarias y comienzan a desarrollarse los Estudios de las Mujeres en distintas universidades" (Ballarín, 2010, 226).

Gracias a la implementación de nuevas políticas públicas se ha logrado la participación de la mujer en estos espacios, así se da paso a una equidad soñada, que no alcanza aún el equilibrio ideal porque "gender inequality is still present in the highest levels of the education system, the university, in spite the fact that the system is based on principals such as equali-ty, merit and capacity" [la desigualdad de género sigue presente en los niveles más altos del sistema educativo, la universidad, a pesar de que el sistema se basa en principios como la igualdad, el mérito y la capacidad ] (Montes y Groves, 2019: 2). Pues la inequidad de género tiene efectos colaterales que no permiten un desarrollo generador del bienestar de grupos femeninos.

Existen estudios, de entidades e individuos, que denotan la invisibilización de la mujer en actividades científicas, por ejemplo, el caso de Mileva Maric, primera esposa de Albert Einstein, mujer de inteligencia privilegiada, compañera de trabajo durante los años más exitosos de la actividad científica del físico. Fue una esposa denigrada que siempre se mantuvo en un segundo plano a pesar de ser motor y partícipe de explicaciones científicas que lograron obtener de manera conjunta, sin embargo, el reconocimiento siempre fue para Einstein, quien ganó el premio nobel que sirvió para cuidados de su hijo esquizofrénico, según los acuerdos dados en el divorcio. Finalmente termina siendo una magnífica maestra de Física a pesar de la gran carga de cuidar a su hijo (Hernández, 2011).

La autora Teresa Ortiz (2002) presenta una ponencia basada en su investigación, en la que intentó demostrar cómo se define al sexo o género femenino y cómo este interviene en las ciencias médicas durante el transcurso de la historia. Realizó el estudio en documentos escritos e investigaciones correspondientes a las dos últimas décadas del siglo XX.

A continuación, voy a presentar algunos resultados de investigación históricomédica realizada con una perspectiva de 
género y centrada en las formas en que la ciencia médica ha construido las categorías mujer y la diferencia sexual. La metodología se basa en el análisis de los discursos contenidos en textos médicos de diferentes épocas, textos significativos en su tiempo, en los cuales atendemos especialmente a la presencia de valores sexistas y metáforas que remiten a discriminación de las mujeres y que, según nuestra hipótesis, jugaron un papel importante en la legitimación social y en la naturalización de patrones culturales. [...] Un ejemplo muy significativo de este proceso es la sexualización de los esqueletos, que empezó a finales del siglo XVIII y convirtió a los esqueletos en receptáculos de todos los valores y de toda la política sexual de la época. En las definiciones de los esqueletos de hombre y de mujer se reprodujeron y naturalizaron los ideales burgueses de masculinidad y feminidad y los roles sociales que se atribuian a los hombres y a las mujeres, es decir, los esqueletos reproducen y encarnan los valores de género característicos de su época (Ortiz, 2002, 32 y 35).

En México las autoras Sánchez y Corona (2009) realizaron un estudio sobre el acceso de las mujeres a la educación superior. Los resultados de la investigación reflejan que con el pasar de los años aumentó la cantidad de matrículas femeninas a la universidad. Sin embargo, la situación respecto a la inserción de ellas a la ciencia aún guarda sesgos discriminatorios que favorecen al sexo masculino.

El reflejo de la situación infravalorada de las mujeres en el trabajo científico no es aislado, es síntoma de un entorno estructural que en general representa menor oportunidad de crecimiento de las mujeres. La doble o triple jornada laboral, la valoración diferenciada por el mismo trabajo, la falta de espacios que permitan desarrollarse, por ejemplo, los límites de edad para ingresar a ciertos grados académicos (que no coinciden con los ciclos vitales), entre otras variables, dan forma a una serie de condiciones que determinan la situación de las mujeres. [...] Aunque en algunas áreas las mujeres y los hombres tienen acceso en la misma proporción a la educación superior a nivel licenciatura y aún en posgrado, hay mecanismos en las maneras de acceder a los estímulos, reconocimientos y distribución de recursos. Se trata de territorios de mayor jerarquía y poder, con lo que se mantiene una orientación tradicional masculina en las instituciones y en la creación de nuevo conocimiento. Así, aunque es innegable el valor de la incorporación femenina en la mayor parte de la matrícula de la educación superior, hay que tener cuidado con el manejo de cifras, no confundir el acrecentamiento con una representación paritaria en el campo de la academia, de la ciencia y de la toma de decisiones (Sánchez y Corona, 2009, 75).

Otro estudio realizado (Castillo, 2018) en la Universidad Nacional de San Agustín de Arequipa demuestra que la mujer continúa siendo objeto de discriminación en temas de ciencia y tecnología, además no gozan de credibilidad y confianza total por parte de los docentes varones.

La data cuantitativa y cualitativa nos muestra que es pertinente hablar de las brechas de género, desde la condición de ser docentes y más si se trata de docentes investigadores o científicos que son un grupo un tanto estilizado. Las situaciones de exclusión de las mujeres de la ciencia y la tecnología, dan cuenta que la dinámica de la vida académica con la vida familiar parte de relaciones de género inequitativas. El grado académico de doctor, el ser docente principal está masculinizado. A nivel del grado académico de Magíster, los datos muestran que el género femenino estudia y se capacita más que los varones, por tanto, hay más magíster mujeres que varones; lo cual muchas veces es percibido con "temor y desconfianza de ser desplazados" [...] Se ve que ha ido aumentando el número de mujeres en la universidad, en especial articuladas a grupos de investigación. Al desarrollo de proyectos de investigación básica y aplicada, 
en proyectos de innovación tecnológica; pero que aún la ciencia es un territorio de tradición masculina en un contexto donde la cultura androcéntrica está muy acentuada en las universidades públicas del país que tienen por población docente la predominancia de varones sobre las mujeres, lo que tipifica un ritmo de acceso y ascenso en las carreras científicas de profesionales mujeres más que lento que el de los varones y está sesgado por campos de conocimiento (Casillo, 2018, 94).

Tanto los estudios realizados con anterioridad como la presente investigación dan cuenta de que la actividad científica de la mujer estuvo presente a lo largo de la historia, pero esta labor tuvo un denominador común en las diferentes épocas, fue el hecho de tratar de opacar y desvirtuar el trabajo científico de la mujer.

\section{Conclusiones}

En el estudio realizado se enfatiza la escritura científica por parte de las mujeres a partir del 2017 en las dos etapas de la investigación, ya para el año 2018 la diferencia entre hombres y mujeres es irrisoria debido a dos motivos fundamentales: la exigencia por parte de las nuevas políticas públicas en la recategorización de docentes y la otra es el nivel de producción científica determinado por la SENESCYT (Secretaría de Educación, Ciencia, Tecnología e Innovación) para el ascenso de categoría de las universidades, esto conllevó a un trabajo conjunto de autores y autoras internos e internas y autoridades en una nueva confrontación con los reglamentos del CACES (Consejo de Aseguramiento de la Calidad de la Educación Superior) cuando se habla de la investigación científica. Pues, "aunque las mujeres son minoría en el campo de la ciencia, cada vez son más las que se unen y desarrollan importantes proyectos en este espacio dominando por el género masculino" (Coello, 2017).
La investigación científica es un reto para los docentes, sean hombres o mujeres, especialmente, para mantener la acreditación de las universidades, proceso en el que una "retroalimentación entre la investigación y las experiencias educativas reales supondrá un compromiso que suprimirá la visión estereotipada del género, la discriminación y la violencia en beneficio de una mejor convivencia e igualdad social" (Prendes, García y Solano, 2020, 20). "Un aspecto más que podría estar asociado a la productividad científica es el prestigio de la institución, en tanto los docentes investigadores sienten un mayor respaldo" (Gordillo, 2017, 58).

Hay que destacar que, según los resultados que se obtuvo en la investigación, la mujer marca el aporte de producción científica en el área de Ciencias Sociales a diferencia de los hombres que lo hacen en Ciencias Exactas en el período 2016-2018. A partir del 2016 la escritura científica toma un descenso en la categoría varones dando énfasis y oportunidad a las mujeres en el período 2014-2018.

Actualmente la escritura científica es uno de los principales ejes del crecimiento académico en los centros de educación superior, lo cual demuestra que existe permanente acción investigativa -deber primordial de la labor universitaria- por parte de la planta docente; a la vez, se logra establecer una relación entre investigadores/as que se desenvuelven en el mismo campo de investigación y, gracias a la escritura, es posible llegar a la comunidad para transmitir el conocimiento. En este quehacer las mujeres demuestran tanto trabajo y talento como los hombres.

\section{Bibliografía}

Agudo, Y. (2006). El lado oscuro de la mujer en la investigación científica: ¿es la ciencia una "empresa" masculina? Cuestiones de Género, 1. 15-57. http://revpubli.unileon.es/ 
index.php/cuestionesdegenero/article/ view/3852/2727

Alic, M. (2005). El legado de Hipatia. Historia de las mujeres en la ciencia desde la antigüedad hasta fines del siglo xix (2da. Ed.). Siglo XXI Editores. https://books.google.es/ books?id=yFEdvT11QioC $\&$ printsec=frontco ver\#v=onepage\&q\&f=false

Alzate, C. (2017). Disciplinando cuerpos y escritura. Agripina Samper sobre George Sand, las mujeres y la literatura (1871). Anclajes, 21 (3). 7-24. 10.19137/anclajes-2017-2132

Ayllón, D. (s. f.). Las Mujeres en la prehistoria y en la historia antigua. Consultado el 30 de enero de 2021. https://www.juntadeandalucia.es/educacion/portals/delegate/ content/4ba061aa-338e-40e2-874d313ee6ef3f04\#: : text $=$ La\%20 sociedad\%20prehist\%C3\%B3rica\%20era\%20 bastante,tareas $\% 20$ entre $\% 20$ hombres \%20y\%20mujeres.\&text=Las\%20 mujeres $\% 20$ guardaban $\% 20$ en $\% 20$ sus,y\%20dirigentes $\% 20$ de $\% 20$ la $\% 20$ civilizaci\%C3\%B3n

Ballarín, P. (2010). Entre ocupar y habitar. Una revisión historiográfica sobre Mujeres y Universidad en España. Arenal, 17(2). 223-254. https://revistaseug.ugr.es/index.php/ arenal/article/view/1450/1618

Castañón, L. (2013). George Sand, una mujer de novela. Revista Melibea 7. 133-142. https://bdigital.uncu.edu.ar/8927

Castillo, R. (2018). Diferencias visibles e invisibles de las mujeres en la ciencia. Universidad Nacional de San Agustín de Arequipa, Perú, 2017. Ciencias Sociales. Revista Académica Indexada de la Facultad de Ciencias Sociales de la Universidad Central del Ecuador, 1(40). 79-97. https://revistadigital.uce.edu.ec/index.php/CSOCIALES/article/view/1251

Científicas de acá. Consultado el 30 de marzo de 2021. https://www.cientificasdeaca.com/ listado

Cobo, R. (2014). Aproximaciones a la teoría crítica feminista. Boletín del Programa de Formación Nº 1. Comité de América Latina y el Caribe para la Defensa de los Derechos de las Mujeres - CLADEM. Programa de Formación N. 1.

Coello, C. (2017, Febr 22). Las mujeres ecuatorianas suman protagonismo en la ciencia médica. La Academia Ecuatoriana de Medicina solo tiene 2 mujeres miembros de número. Ediciónmédica. Consultado el 23 de enero de 2021. https://www.edicionmedica.ec/secciones/profesionales/ las-mujeres-ecuatorianas-van-sumandoprotagonismo-en-la-ciencia--89609

Estrella, B. (2016). Fomentando cultura de investigación en la Universidad Central del Ecuador: la perspectiva desde los Proyectos Semilla. Revista de la Facultad de Ciencias Médicas, 41(1). 3-8. https:// revistadigital.uce.edu.ec/index.php/CIENCIAS_MEDICAS/article/view/1168

Gervasoni, J. (2018). Antagonismo de género en las comunidades científicas. Situación en Argentina y América Latina. En M. Pessina (Ed.), Impacto de las Mujeres en la Ciencia. Efecto del género en el desarrollo y la práctica científica (pp. 65-90). CIESPAL. https://ciespal.org/wp-content/ uploads/2019/06/Mujeres-en-la-cienciaDigital-VFJUL19.pdf

Gordillo, A. (2017). La escritura científica: Una revisión temática. Signo y Pensamiento, (36)71, 52-64. https://www.redalyc.org/ pdf/860/86054913003.pdf

Guil-Bozal, A. (2016). Techos universitarios de cristal blindado. Investigaciones Feministas, 7(2), 25-39. https://doi.org/10.5209/ INFE.53964

Guzmán, M. (2016). La presencia del género en la vida personal y laboral de académicasinvestigadores Universitarias. Géneros, 23(19), 7-29. http://revistasacademicas. ucol.mx/index.php/generos/article/ view/1206/pdf

Hernández, M. (2011, Dic 17). Mileva Maric, la sombra de Einstein. Personas con Historia. Perfiles de personajes históricos que merece la pena conocer. Consultado el 23 de marzo de 2020. http://personasconhistoria.blogspot.com/2011/12/mileva-maricla-sombra-de-einstein.html 
Lamas, M. (2009). Cuerpo: diferencia sexual y género. Sevillana Ediciones Generales. https://libroschorcha.files.wordpress. com/2018/05/cuerpo-diferencia-sexualy-genero-marta-lamas.pdf

Lander, M. F. (2011). La encrucijada de Manuela Sáenz en el imaginario cultural latinoamericano del siglo xxi. Araucaria, 13(25), 165-181. https://revistascientificas.us.es/ index.php/araucaria/article/view/1349

Marín-San Martín, O. (2020). La representación de las mujeres prehistóricas en los textos escolares de Historia, Geografía y Ciencias Sociales en Chile (2010-2018). Estudios Pedagógicos, 46(1), 7-31. doi:10.4067/S071807052020000100007

Mingo, A. (2020). El tránsito de estudiantes universitarias hacia el feminismo. Perfiles Educativos, 42(167), 10-30. https://doi. org/10.22201/iisue.24486167e.2019. 167.59063

Montes, E. y Groves, T. (2019). Micro-machismo and discrimination in academia: The violation of the right to equality in university [Micro-machismo y discriminación en la academia: La violación del derecho a la igualdad en la universidad]. Culture \& History Digital Journal, 8(1), 01-09. https:// doi.org/10.3989/chdj.2019.010

Ortiz, T. (2002). El papel del género en la construcción histórica del conocimiento científico sobre la mujer. En E. Ramos (Ed.), La salud de las mujeres: hacia la igualdad de género en salud (29-42). Ministerio de Trabajo y Asuntos Sociales-Instituto de la Mujer. http://hdl.handle.net/10481/15380

Padrón, C., Quesada, N., Pérez, A., González, P. y Martínez, L. (2014). Aspectos importantes de la redacción científica. Revista de Ciencias Médicas, 18(2), 362-380. http:// scielo.sld.cu/pdf/rpr/v18n2/rpr20214.pdf

Peiró, S. (2018). Escandalosas. 80 mujeres de armas tomar. Ediciones Casiopea. https:// books.google.com.ec/books? $\mathrm{id}=$ IgmMDW AAQBAJ\&pg=PT46\&lpg=PT46\&dq=por $+s$ us+ideales+sociales $+y+$ humanitarios $+G$ eorge + Sand $\&$ source $=$ bl\&ots $=$ ERafGyiKZ C\&sig=ACfU3U28HXZKctnRKUAJE_6P1qd dgfgEQ\&hl=es\&sa $=$ X\&ved $=2$ ahUKEwiBp IjK4PnmAhXLqlkKHdwhCwsQ6AEwA3oE CAoQAQ\#v=onepage $\& q=$ por\%20sus20ideales\%20sociales\%20y\%20humanitarios\%20George\%20Sand\&f=false

Pérez, E. (2018). Nuevos conocimientos desde una perspectiva feminista. En M. Pessina (Ed.), Op Cit.

Prendes-Espinosa, M., García-Tudela, P., \& Solano-Fernández, I. (2020). Gender equality and ICT in the context of formal education: A systematic review. [Igualdad de género y TIC en contextos educativos formales: Una revisión sistemática]. Revista Científica de Comunicación y Educación Comunicar, XXVIII(63), 9-20. https://doi. org/10.3916/C63-2020-01

Sánchez, A. (2001). Críticas Feministas a las Ciencias Biomédicas. En J. A. López_Cerezo \& J. Sánchez (Eds.), Ciencia, Tecnología, Sociedad y Cultura en el cambio del siglo (297-322). Biblioteca Nueva. Organización de Estados Americanos.

Sánchez, M. y Corona, T. (2009). Inserción de las mujeres en la ciencia. Historia y Filosofía de la Medicina, 145(1), 71-76. https://www. anmm.org.mx/GMM/2009/n1/71_vol_145_ n1.pdf

Varela, H. (2012). Iguales, pero no tanto. El acceso limitado de las mujeres a la esfera pública en México. Confines, 8(16), 39-67. http://www.scielo.org.mx/pdf/confines/ v8n16/v8n16a3.pdf

Vargas, C., Lutz, M., Apuzinski, C. y Arancibia, M. (2020). Género, mujeres e investigación científica. Medwave, 20(2). 10.5867/medwave.2020.02.7857 